\title{
Curriculum for endoscopic submucosal dissection training in Europe: European Society of Gastrointestinal Endoscopy (ESGE) Position Statement
}

Authors

Pedro Pimentel-Nunes $1,2,3,{ }^{*}$, Mathieu Pioche4, ${ }^{4}$, Eduardo Albéniz ${ }^{5,6}$, Frieder Berr ${ }^{7}$, Pierre Deprez ${ }^{8}$, A. Ebigbo ${ }^{9}$, Pieter Dewint $^{10,11}$, Amyn Haji ${ }^{12}$, Alba Panarese ${ }^{13}$, Bas L. A. M. Weusten ${ }^{14,15}$, Evelien Dekker ${ }^{16}$, James E. East ${ }^{17,18}$, David S. Sanders ${ }^{19}$, Gavin Johnson ${ }^{20}$, Marianna Arvanitakis ${ }^{21}$, Thierry Ponchon ${ }^{4}$, Mário Dinis-Ribeiro', ${ }^{1,}$ Raf Bisschops ${ }^{22}$

Institutions

1 Gastroenterology Department, Portuguese Oncology Institute of Porto, Porto, Portugal

2 Center for research in health technologies and information systems (CINTESIS), Faculty of Medicine, University of Porto, Porto, Portugal

3 Surgery and Physiology Department, Faculty of Medicine of the University of Porto, Porto, Portugal

4 Gastroenterology division, Edouard Herriot Hospital, Lyon, France

5 Gastroenterology Department, Endoscopy Unit, Complejo Hospitalario de Navarra, Pamplona, Spain

6 Navarrabiomed, Universidad Pública de Navarra, IdiSNa, Pamplona, Spain

7 Department of Medicine I, Paracelsus Medical University, Salzburg, Austria

8 Department of Hepato-Gastroenterology, Cliniques universitaires Saint-Luc, Université Catholique de Louvain, Brussels, Belgium

9 Department of Gastroenterology, Universitätsklinikum Augsburg, Germany

10 Department of Gastroenterology and Hepatology, AZ Maria-Middelares, Ghent, Belgium

11 Department of Gastroenterology and Hepatology, UZA, Antwerp, Belgium

12 King's Institute of Therapeutic Endoscopy, King's College Hospital, Denmark Hill, London, UK

13 National Research Institute Specialized in Gastroenterology “S. de Bellis” - IRCCS, Castellana Grotte (BA), Italy

14 Department of Gastroenterology and Hepatology, University Medical Center Utrecht, Utrecht University, The Netherlands

15 Department of Gastroenterology and Hepatology, St Antonius Hospital Nieuwegein, The Netherlands

16 Department of Gastroenterology and Hepatology, Academic Medical Center, Amsterdam, The Netherlands
17 Translational Gastroenterology Unit, Nuffield Department of Medicine, Experimental Medicine Division, John Radcliffe Hospital, University of Oxford, Oxford, UK

18 Oxford NIHR Biomedical Research Centre, Oxford, UK

19 Academic Unit of Gastroenterology, Royal Hallamshire Hospital, Sheffield, UK

20 University College London Hospitals, London, UK

21 Department of Gastroenterology, Erasme University Hospital, Brussels, Belgium

22 Department of Gastroenterology and Hepatology, University Hospitals Leuven, and TARGID, KU Leuven, Belgium

Bibliography

DOI https://doi.org/10.1055/a-0996-0912

Published online: 30.8.2019 | Endoscopy 2019; 51: 980-992

(c) Georg Thieme Verlag KG Stuttgart · New York

ISSN 0013-726X

Corresponding author

Pedro Pimentel-Nunes, MD PhD, Gastroenterology

Department, Portuguese Oncology Institute of Porto, Rua Dr. Bernardino de Almeida, Porto, Portugal

Fax: +351-22-5513646

pedronunesml@gmail.com

丹 Appendix 1s

Online content viewable at:

https://doi.org/10.1055/a-0996-0912

Additional online content available on the ESGE website at: https://www.esge.com/esd-training-curriculum/

\section{MAIN RECOMMENDATION}

There is a need for well-organized comprehensive strategies to achieve good training in ESD. In this context, the European Society of Gastrointestinal Endoscopy (ESGE) have developed a European core curriculum for ESD practice across Europe with the aim of high quality ESD training. 
Advanced endoscopy diagnostic practice is advised before initiating ESD training. Proficiency in endoscopic mucosal resection (EMR) and adverse event management is recommended before starting ESD training

ESGE discourages the starting of initial ESD training in humans. Practice on animal and/or ex vivo models is useful to gain the basic ESD skills. ESGE recommends performing at least 20 ESD procedures in these models before human practice, with the goal of at least eight en bloc complete resections in the last 10 training cases, with no perforation. ESGE recommends observation of experts performing ESD in tertiary referral centers. Performance of ESD in humans should start on carefully selected lesions, ideally small $(<30 \mathrm{~mm})$, located in the antrum or in the rectum for the first 20 procedures. Beginning human practice in the colon is not recommended. ESGE recommends that at least the first 10 human ESD procedures should be done under the supervision of an ESD-proficient endoscopist.

Endoscopists performing ESD should be able to correctly estimate the probability of performing a curative resection based on the characteristics of the lesion and should know the benefit/risk relationship of ESD when compared with other therapeutic alternatives. Endoscopists performing ESD should know how to interpret the histopathology findings of the ESD specimen, namely the criteria for low risk resection ("curative"), local risk resection, and high risk resection ("non-curative"), as well as their implications. ESD should be performed only in a setting where early and delayed complications can be managed adequately, namely with the possibility of admitting patients to a ward, and access to appropriate emergency surgical teams for the organ being treated with ESD.

\section{SOURCE AND SCOPE}

This position statement is an official statement of the European Society of Gastrointestinal Endoscopy (ESGE). It provides recommendations for a European core curriculum aimed at providing high quality training in ESD. The recommendations presented are based on a consensus among endoscopists considered to be ESD experts who are involved in ESD training and training courses in Europe.

\section{Introduction}

Endoscopic submucosal dissection (ESD) appeared more than a decade ago in Japan as a new method to achieve en bloc resection of superficial neoplasms without any size limit. Since then, the technique has evolved greatly and shifted from the stomach to the esophagus and the colon. It expanded first to Eastern Asia, then to Europe and the rest of the world [1].

The advantage of ESD over endoscopic mucosal resection (EMR) lies in its ability to achieve en bloc resection of lesions regardless of the tumor size or the presence of fibrosis, avoiding piecemeal resection and consequently local recurrence. However, it comes with the drawback of longer procedure times, as well as an increased risk of bleeding and perforation [2]. For these reasons, the Western world remained cautious about implementing ESD for several years. One of the most important limitations for the spread of this technique outside Asia was the lack of local experts. Strategies to overcome this limitation have come mostly from Western endoscopists who individually visited Japanese expert centers and observed ESD on real patients [3]. However, going to Eastern countries to learn this technique is not feasible for most Western endoscopists. Moreover, hands-on training on patients for foreign physicians is not easily nor legally allowed either in Japan or in other parts of the world.
Therefore, there is a clear need for well-organized comprehensive strategies to achieve good training in ESD. In this context, the European Society of Gastrointestinal Endoscopy (ESGE) initiated the development of this ESD curriculum for postgraduate training to improve and safeguard ESD practice in Europe. The recommendations presented in this curriculum ( $\triangleright$ Table 1 ) are based on a consensus among endoscopists considered to be ESD experts who are involved in ESD training and training courses in Europe.

$\begin{array}{ll}\text { ABBREVIATIONS } \\ \text { EMR } & \text { endoscopic mucosal resection } \\ \text { EMRb } & \text { band-ligation EMR } \\ \text { EMRC } & \text { cap-assisted EMR } \\ \text { ESD } & \text { endoscopic submucosal dissection } \\ \text { ESGE } & \text { European Society of Gastrointestinal Endoscopy } \\ \text { ESU } & \text { electrosurgical unit } \\ \text { GI } & \text { gastrointestinal } \\ \text { IPCL } & \text { intrapapillary capillary loop } \\ \text { JNET } & \text { Japan NBI Expert Team } \\ \text { NBI } & \text { narrow-band imaging } \\ \text { NICE } & \text { NBI international colorectal endoscopic classifi- } \\ & \text { cation } \\ \text { NSAID } & \text { nonsteroidal anti-inflammatory drug } \\ \text { OTSC } & \text { over-the-scope clip } \\ \text { PICO } & \text { population/patient; intervention/indicator; } \\ & \text { comparator/control; outcome } \\ \text { WHO } & \text { World Health Organization }\end{array}$


- Table 1 List of recommendations for training in endoscopic submucosal dissection (ESD).

\section{Skills/competence to start ESD}

Advanced endoscopy diagnostic practice is advised before initiating ESD training

Training in ESD should be considered only by fully trained endoscopists. Proficiency in EMR and adverse event management is recommended before starting ESD training

Knowledge of the "ESD theory" is necessary before and during training

\section{Training}

Live conferences and meetings are suggested before and during ESD training

ESGE discourages the starting of initial ESD training in humans

Practice on animal and/or ex vivo models is useful to gain the basic ESD skills. ESGE recommends performing at least 20 ESD procedures in these models before human practice, with the goal of at least eight en bloc complete resections in the last 10 training cases, with no perforation

ESGE recommends supervision during training as it seems effective in improving the skills of trainees

In order to understand strategies and risk management, ESGE recommends observation of experts performing ESD in tertiary referral centers. At least 20 ESD procedures observed and five procedures as assistant, ideally within a short period of time, are recommended

Performance of ESD in humans should start on carefully selected lesions, ideally small ( $<30 \mathrm{~mm}$ ), located in the antrum or in the rectum for the first 20 procedures (initial period). Beginning human practice in the colon is not recommended

ESGE recommends that at least the first 10 procedures in humans should be done under the supervision of an ESD-proficient endoscopist

\section{Knowledge and maintaining competence}

Endoscopists involved in ESD should have specific knowledge of the instrumentation, technique, and electrosurgical equipment

Endoscopists performing ESD should be able to correctly estimate the probability of performing a curative resection based on the characteristics of the lesion and should know the benefit/risk relationship of ESD when compared with other therapeutic alternatives

Endoscopists performing ESD should know how to interpret the histopathology findings of the ESD specimen, namely the criteria for low risk resection ("curative"), local risk resection, and high risk resection ("non-curative"), as well as their implications

Ideally, endoscopists properly trained in ESD should start performing ESD at their own center only after an ESD expert has confirmed that they have the knowledge and skills to start performing ESD

ESD should be performed only in a setting where early and delayed complications can be managed adequately, namely with the possibility of admitting patients to a ward, and access to appropriate emergency surgical teams for the organ being treated with ESD. In addition, centers performing ESD should have access to expert gastrointestinal pathology

In order to maintain proficiency in ESD, ESGE recommends a minimum case load of 25 ESD procedures per year

All procedures should be registered in a prospective database covering items such as endoscopic classification, location and size of the lesion, technique used, en bloc resection rate, complication rates, time of procedure, R0 resection rate, and final histopathology (including type of resection). En bloc resection rates should be above $90 \%$, and the perforation rate should be below $3 \%$, with a lower than $1 \%$ need for surgery because of complications

EMR, endoscopic mucosal resection; ESGE, European Society of Gastrointestinal Endoscopy.

\section{Aims}

The primary aims of this curriculum are:

- to develop a European core curriculum for ESD practice across Europe that results in a high quality of ESD training, independently of the center, hospital, location, or endoscopist, through the setting of minimum standards for the practice of the technique

- to define the skills and competence that endoscopists should have before considering ESD training

- to define a training program for endoscopists who want to start ESD practice in their center.
The secondary aims are:

- to increase awareness of the skills, knowledge, and difficulties inherent in the practice of ESD

- to support individual endoscopy departments, national societies, and official bodies in developing local or national recommendations for ESD training and practice

- to define the knowledge and minimum case load that endoscopists should have to maintain proficiency in the ESD technique.

\section{Methods}

The development of this curriculum is based on a consensus among expert practitioners of ESD who are involved in ESD training and training courses in Europe [4]. On behalf of the 
ESGE curricula working group initiative [5], R.B. (ESGE curricula working group chair) invited P.P.N. to become ESGE section chair for the ESD curriculum. A call for participants opened in July 2017 and R.B. and P.P.N. analyzed all the applications. Based on their curriculum, ESD experience, and publications, as well as motivation, in December 2017, the authors of this document were selected to become members of the ESD curriculum working group. In February 2018, all the group members had a meeting in Dusseldorf, Germany. At this meeting, the methodology to be applied was discussed and different tasks were divided between the group members.

Three different tasks were decided upon:

1. What are the skills and competency requirements prior to starting ESD?

2. What are the training requirements?

3. What should the knowledge and experience be to maintain competence?

Different PICO questions (where P stands for population/patient, I for intervention/indicator, C for comparator/control, and $\mathrm{O}$ for outcome) were defined for each of these questions. An evidence-based Delphi process was used to develop consensus statements. Literature searches were performed using PubMed/Medline, and preliminary sentences were proposed based on the available literature and expert opinion. In April 2018 in Budapest, the group members met again, discussed the proposed sentences, and agreed on standard terminology, the need for auditable quality indicators, and the formulation of the ESD training curriculum for trainees under expert supervision during the initial learning curve for clinical ESD.

Based on all comments and suggestions, P.P.N. and M.P. evaluated and grouped every statement and the evidence into a document with all the necessary bibliography, elaborating a first draft of the curriculum that was circulated among the group members in October 2018. Sentences were voted on online by all the group members. Discussion and an initial decision on the recommendations took place in a face-to-face meeting in October 2018 in Vienna, Austria. At this stage, changes were made if necessary and sentences with less than $75 \%$ agreement were excluded from the curriculum. Sentences were voted on online again by all the group members, along with a further group of physicians not involved in the development of this curriculum until a consensus was reached.

\section{Results}

\section{Skills/competence to start ESD}

RECOMMENDATION

Advanced endoscopy diagnostic practice is advised before initiating ESD training.

Level of agreement $95 \%$.

As recommended in the ESGE guidelines of 2015 [6], lesion assessment by an experienced endoscopist using advanced diagnostic techniques (virtual or dye-based chromoendoscopy with or without magnification) is an essential prerequisite to ESD resections. In fact, ESD with curative intent is only justified in the various ESGE guidelines when lesions are clearly neoplastic and do not show features of deep invasion [6-8]. So, mastering classifications like Paris [9], Inoue's intrapapillary capillary loop (IPCL) [10,11], and Sano's [12] for esophageal lesions; simplified narrow-band imaging (NBI) $[13,14]$, vessel plus surface $[15,16]$, and depth-predicting scores for superficial gastric lesions [17]; and Kudo's [18], the narrow-band imaging international colorectal endoscopic (NICE) [19], and/or Japan NBI Expert Team (JNET) $[20,21]$ for colonic lesions is pivotal in decision-making when determining the appropriate lesions for which ESD is indicated and to correctly define the margins of the lesions. The endoscopic reports of ESD trainees on any gastrointestinal (GI) neoplasia must contain: the macroscopic type and characteristics; the microvascular and microsurface structure; the endoscopic diagnosis of predicted tumor category; and the indication for recommended resection technique. Therefore, advanced endoscopic diagnostic skills are required and should be mastered before the performance of any ESD procedure.

\section{RECOMMENDATION}

Training in ESD should be considered only by fully trained endoscopists. Proficiency in EMR and adverse event management is recommended before starting ESD training. Level of agreement $100 \%$.

An endoscopy background is needed to begin ESD procedures safely. Japanese experts consider that a minimum of 4 years of endoscopy experience after graduation is needed [22], although they underline the importance of acquiring the skills whatever time is needed for this [23]. As ESD is a precise and challenging procedure, operators should have knowledge of therapeutic endoscopy and particularly of resection of superficial digestive neoplasia (i. e. using EMR) [22]. An objective indicator to consider starting ESD training is to have performed at least 1000 upper Gl endoscopies, because it has been shown that trainees with that number of endoscopies can efficiently acquire gastric ESD skills [24]. For colorectal ESD, a minimum of 500 colonoscopies appears to be required before considering training [25]. ESD trainees must acquire proper handling and control of the endoscope with all left-handed angulations of the scope, and rotation of the shaft using the left wrist and arm. Right-handed controls of insertion/retraction of the scope may support rotation of the shaft, even in diagnostic procedures [26].

Overall, management of adverse events is also required before starting to perform the ESD technique, with experience at least in hemostatic techniques for active bleeding and closure techniques for perforations using clips, over-the-scope clips (OTSCs), endoscopic suturing, and stent placement (for esophageal perforations). Expertise in hemostasis is strongly advised 
because most of the difficulties during ESD procedures and training are related to uncontrolled bleeding [24, 27].

ESD is an advanced endoscopy technique demanding precise control of the endoscope. Obviously, beginning endoscopy with the ESD technique is not advised and previous experience in endoscopic resection using EMR is logically recommended. All of the reports on the ESD learning curve have involved experienced endoscopists who are already routinely performing EMR. From a technical point of view, maneuverability of the scope, placement, submucosal injection, and management of adverse events are required to perform EMR. The precision required for ESD, with meticulous movements, is a further step that would seem impossible to master without baseline EMR skills [28-31]. At the time of writing this curriculum, initial ESD teaching without previous EMR skills has not been evaluated nor compared with the training of EMR-skilled endoscopists. In units with large volumes of ESD cases, some trainees may have early access to ESD without a large experience in EMR but the basic skills of injection, hemostasis, and perforation closure should be mastered before undertaking any independent ESD procedure.

Cap-assisted EMR (EMRc) or band-ligation EMR (EMRb) are advanced resection techniques essentially used for esophageal and, to a lesser degree, gastric and rectal lesions. Their techniques are different from the ESD technique and this step does not seem absolutely necessary to pave the ESD training pathway. ESD training programs based on specific EMRb or EMRc experience have never been specifically tested, as their specific technical skills do not seem to be linked to ESD skills. However, when ESD is proving difficult to perform, knowledge and experience with these techniques may be helpful as they may be used as rescue therapeutic options in some situations.

\section{RECOMMENDATION}

Knowledge of the "ESD theory" is necessary before and during training.

Level of agreement $95 \%$.

Before beginning ESD in models, the theory has to be understood [24]. Starting to learn a new technique has little value without a knowledge of its aims, indications, and the results that can be expected. Learning the different steps (marking, injection, cutting, dissection), the basic strategy (use of gravity or traction), and the use of tools (needle-type knives, insulated tools, water jet) is a prerequisite. A lot of information is now available on ESD technique (books, DVDs, or on the web, including videos). Attending live demonstrations, meetings, and ESD procedures performed by experts is recommended to understand the steps and the goals of this technique and in parallel to improve diagnostic skills when faced with neoplastic lesions. The ESD trainee should have a real perspective of the workings of an ESD expert center if they are to implement similar practices in their own center.

\section{Training}

\section{RECOMMENDATION}

Live conferences and meetings are suggested before and during ESD training.

Level of agreement $95 \%$.

\section{RECOMMENDATION}

ESGE discourages the starting of initial ESD training in humans.

Level of agreement $95 \%$.

Once the basic theoretical knowledge has been mastered, and before beginning ESD in models, attending live demonstrations or meetings is probably a good way (controlled information) to learn the prerequisites from experts [22]. These attendances may help trainees to learn some tricks, understand techniques with different devices, in both easy and difficult locations, with the aim of improving their performance. Nevertheless, this point is based on expert opinion and clinical evidence is still lacking [32], because it has not yet been demonstrated that attendance at live demonstrations is able to improve ESD outcomes in trainees.

With regard to beginning ESD training in humans, it is our opinion that this should be strongly discouraged. The complexity of the technique and the potential serious side effects, as well as several alternative options for training, are strong reasons to avoid taking the initial training steps in humans. A French study on initial rectal ESD experience in humans without supervision demonstrated how dangerous ESD can be in nonexperienced hands [33]. In this study, the initial perforation rate was $34 \%$ and the initial $\mathrm{R} 0$ resection rate only $52 \%$. Therefore, beginning ESD training in humans is strongly discouraged as it may be both dangerous and ineffective.

\section{RECOMMENDATION}

Practice on animal and/or ex vivo models is useful to gain the basic ESD skills. ESGE recommends performing at least 20 ESD procedures in these models before human practice, with the goal of at least eight en bloc complete resections in the last 10 training cases, with no perforation.

Level of agreement $95 \%$.

\section{RECOMMENDATION}

ESGE recommends supervision during training as it seems effective in improving the skills of trainees. Level of agreement $95 \%$. 
There is some clinical evidence to support the positive impact of animal model training before beginning ESD in humans, but prospective comparative studies are still not available. Nevertheless, training in a live porcine model was considered very realistic by participants compared with the human setting and was highly appreciated as a learning tool [34,35]. Moreover, the outcomes of ESD, even with previous animal training albeit not in the respective human organ [33], do not encourage the proposal of comparative studies between trainees who have experienced previous animal training and those who have not.

ESD training is associated with a clear learning curve both in animal models and in human procedures [36-40]. Hands-on training on animal models produces an improvement in ESD outcomes, with an increase in the complete resection rate and a decrease in the perforation rate $[30,31,38,41]$. In an American experience with three trainees who performed 30 procedures each, the inflexion of the learning curve was achieved after nine procedures on a colonic model, although students were still progressing throughout the 30 procedures [41]. Animal model training is also effective in improving the skills needed for the management of ESD adverse events (bleeding and perforation) [42].

Despite the lack of evidence demonstrating a relationship between ESD results in animal training and subsequent initial human experience, ESGE recommends an initial experience in animal models before human practice. Different animal models (ex vivo pig stomach or esophagus, bovine or pig colon, living animal models) exist, but there are no comparative data on the training capacity of these different models. For initial experience, ex vivo models are probably sufficient to allow training without sacrificing animals. In expert centers with strong supervision, initial training experience in humans may sometimes be proposed but clinical evidence is lacking to sustain this strategy.

In Japan, the number of ex vivo or animal training courses needed before starting ESD training in humans is five or less [24]. However, learning curves are different from one trainee to another; therefore, determining a minimum number of courses and/or procedures appears difficult. A performance objective appears more relevant and each student should record their results (complete resections, perforations) during animal training (Appendix 1s; see online-only Supplementary material). ESGE proposes a quality goal of a complete resection rate of at least $80 \%$ without perforations during 10 consecutive procedures to define a trained student, as previously suggested [31, 43].

In a prospective comparative study in a bovine rectum model, $20 \%$ of 20 students without any supervision reached this goal after 10 procedures, $50 \%$ after 20 procedures, and $55 \%$ after 30 procedures [31]. With virtual supervision, the rate of students who achieved the goal was $32 \%, 63 \%$, and $74 \%$ after 10,20 , and 30 procedures, respectively, underlining the positive effect of supervision during animal training. In a study from USA and Japan, video-based post-procedure analysis and recommendation by an expert allowed two students to com- plete three successive $\mathrm{R} 0$ resections without perforations after 25 procedures [44].

The role of dedicated software or video watching is not yet clearly defined. When point-by-point supervision is available, this was shown to increase the number of students who reached an $80 \%$ rate of complete resections without perforations after 30 procedures [31]. These results underline the effectiveness of supervision during training [44], either with on-site experts if possible or with virtual supervision if a local expert is not accessible.

To reach the goal, ESGE recommends a minimum number of 20 procedures, with supervision if possible, but half of the trainees will probably need more training to fulfill the quality threshold of an $80 \%$ rate of en bloc complete resections (all marks visible in the specimen) without perforation in 10 consecutive procedures.

\section{RECOMMENDATION}

In order to understand strategies and risk management, ESGE recommends observation of experts performing ESD in tertiary referral centers. At least 20 ESD procedures observed and five procedures as assistant, ideally within a short period of time, are recommended. Level of agreement $91 \%$.

Observing procedures performed by experts is effective in improving ESD skills, as demonstrated by Draganov et al. [45]. The ESD procedure time was clearly reduced between the preobservation period (63 minutes) and the post-observation period (32 minutes). This study compared nine procedures performed in an animal model before and after an observation period of 5 weeks. Assisting an expert during some procedures is probably a better option than only watching as it increases the involvement and the concentration needed. Furthermore, as these procedures are time-consuming, this might also teach the trainee to be patient, even during bleeding episodes. Japanese experts recommend a minimum of 20 procedures observed and five as an assistant before starting ESD in patients [22]. A high number of procedures observed increases understanding of a wide variety of situations, different organs, and adverse event (bleeding, perforation, and stenosis) management.

\section{RECOMMENDATION}

Performance of ESD in humans should start on carefully selected lesions, ideally small $(<30 \mathrm{~mm})$, located in the antrum or in the rectum for the first 20 procedures (initial period). Beginning human practice in the colon is not recommended.

Level of agreement $95 \%$. 
RECOMMENDATION

ESGE recommends that at least the first 10 procedures in humans should be done under the supervision of an ESDproficient endoscopist.

Level of agreement $91 \%$.

In Japan, experts recommend training in ESD on small lesions $(\leq 20 \mathrm{~mm})$ of the antrum without ulceration or scarring [22], as these lesions are associated with the lowest risk of non-curative resection [46]. Lesions of the mid and upper third of the stomach are far more difficult for beginners to complete ESD $[28,31,47]$. Nevertheless, this recommendation must be adapted to the incidence of each lesion in different parts of the world.

In any scenario, it seems that ESD should be learnt on easy cases before colonic ESD is undertaken. In Hong Kong, despite a previous animal training program, initial experience with colorectal ESD without any previous gastric procedures was dangerous and poorly effective with rates of $32.2 \%$ for R0 resection in the initial experience and $15.5 \%$ for perforations [26]. Results reported by Shiga et al. are less negative but the initial rate of perforation was still $10 \%$ in one study [28] and $12.5 \%$ for another study from the same group [48]. In contrast, endoscopists experienced in gastric ESD produce effective and safe outcomes during the learning curve in colorectal ESD, with an $\mathrm{R} 0$ resection rate of more than $90 \%[37,49]$.

A Japanese study showed the relative safety of rectal ESD for beginners who had experience of only five gastric ESD procedures [28]. Shiga et al. showed that choosing small lesions in the rectum was safer to gain experience than choosing colonic lesions. Furthermore, as demonstrated by lacopini et al. [29], for initial experience in colorectal ESD, the rectum should be preferred rather than the colon to allow a progressive stepwise approach with fewer risks. Rectal location was a predictive factor for success during the learning phase of ESD for trainees without gastric ESD experience [50]. Progressive implementation from the rectum to more difficult parts of the colon is safe and effective, with a perforation rate of only 5.7\% [51]. Because of the gap in difficulty between rectal and colonic $E S D$, it seems reasonable to suggest a progressive move from small lesions of the rectum to the ascending colon and then to the transverse or sigmoid colon, and finally to the cecum where the risk of perforation is the highest [52-54]. Nevertheless, some rectal lesions with big nodular areas or with a history of scarring can be associated with fibrosis and bleeding, making the procedure very difficult. This phenomenon is relatively rare for small lesions. Therefore, after animal training, it appears better to continue with initial human training in safe (rectum) or easy locations (antrum) before starting to undertake procedures in technically difficult locations (colon) or in locations where perforations are highly morbid (esophagus).

Antral lesions of $20-30 \mathrm{~mm}$ are rare in some European countries and should be reserved for beginners but, to train in a relatively short period of time, we also have to consider different locations. Several arguments (incidence, maneuverability, low morbidity of rectal perforations) encourage training in the middle rectum (at least a few $\mathrm{cm}$ above the anus). According to ESGE guidelines, ESD in the colorectum can be considered instead of EMR for selected lesions larger than $20 \mathrm{~mm}$. Therefore, choosing rectal lesions slightly larger than $20 \mathrm{~mm}(<30 \mathrm{~mm})$ would probably be a good option [55]. The avoidance of cases with technical difficulty (scarring, incomplete resections, ulcerative colitis, fibrosis) is also advised [22].

The number of ESDs required for endoscopists to become competent in the technique is not precisely defined. For gastric ESD, 30 procedures was defined as the number necessary to gain proficiency [56]. However, others have suggested that 50 - 100 gastric ESD procedures would be needed for expertise [22]. For colorectal ESD, approximately 30 and 80 procedures are needed to achieve competent and proficient levels of ESD, respectively [57]. In a recent European study, 120 colorectal ESD procedures were needed to reach a plateau of high effectiveness and low morbidity [54]. However, achieving such a high number of procedures does not appear realistic in Europe. The role of supervision has to be re-emphasized and the expert should be present in the necessary procedures for the trainee to be competent. ESGE recommends therefore that at least the first 10 human ESD procedures, ideally per organ, should be done under supervision by an ESD-proficient endoscopist.

Furthermore, particularly in low volume centers, in order to avoid spaced training, mixing practice on animal models with the first human procedures is a good option to maintain regular and frequent ESD practice and to achieve high quality results for $\mathrm{R} 0$ resection and perforation rates [58]. In fact, a step-up training protocol over a 12-month period of 50 observational and supervised ESD procedures, as well as 24 animal procedures, showed excellent results, particularly in the rectum and stomach, with more than $90 \%$ of procedures achieving R0 resections [53].

A logbook and a preclinical database suggested by ESGE for ESD training are available for trainees on the ESGE website (https://www.esge.com/esd-training-curriculum/).

\section{Knowledge and maintaining competence}

\section{RECOMMENDATION}

Endoscopists involved in ESD should have specific knowledge of the instrumentation, technique, and electrosurgical equipment.

Level of agreement $100 \%$.

ESD is a complex and technically demanding procedure. Accordingly, in order to perform safe and effective treatment, while avoiding serious complications, endoscopists should have a full understanding of not only the technique but also the different instruments and the electrosurgical unit (ESU) that are needed to perform a safe ESD $[59,60]$. We recommend that endoscopists should have extensive knowledge of all the devices that can be used for ESD, such as knives, injection agents, caps and hoods, and hemostatic and traction devices, as this information can be important in more difficult and com- 
plex situations [59-62]. In fact, there are several knives available to perform ESD, each one with its own particularities and advantages over others for use in certain situations [59,60, $63,64]$, but without enough evidence to recommend one knife over another. As a general rule, we recommend that endoscopists should use the equipment that they feel comfortable with, ideally the same as they have used in training, but at the same time should know the full ESD "armamentarium" so they can choose other options in more difficult/complex scenarios.

Endoscopists should also know the principles and features of the ESUs that can be used for ESD. In fact, each ESU has its own settings and types of current; the recommended settings vary according not only to the cutting device that is being used but also with the lesions and organs in which the current is applied. Some manufacturers provide specific instructions for performing ESD [65]. In the absence of these, we recommend that endoscopists contact the manufacturer of their own ESU before starting ESD in humans.

\section{RECOMMENDATION}

Endoscopists performing ESD should be able to correctly estimate the probability of performing a curative resection based on the characteristics of the lesion and should know the benefit/risk relationship of ESD when compared with other therapeutic alternatives.

Level of agreement $95 \%$.

\section{RECOMMENDATION}

Endoscopists performing ESD should know how to interpret the histopathology findings of the ESD specimen, namely the criteria for low risk resection ("curative"), local risk resection, and high risk resection ("non-curative"), as well as their implications.

Level of agreement $100 \%$.

When performing ESD, endoscopists are responsible not only for a proper technical execution of the procedure, but also for the clinical decision-making and clinical care. This implies that endoscopists should be able to balance the benefits and risks of ESD against alternative treatment options for that specific disease. As previously stated, they should be familiar with advanced imaging diagnosis. Moreover, depending on the organ, location, type, and other characteristics of the lesion, endoscopists should be able to calculate the probability of performing a curative resection. There are platforms available online that can help endoscopists calculate the a priori probability of a curative resection and also the risk of post-resection bleeding [66]. Even though we recognize that, to avoid more aggressive procedures (like surgery) in patients with several co-morbidities, endoscopists may sometimes assume a low probability of a curative resection yet still proceed to ESD, we recommend that such situations should always be discussed with the patient, and ideally within a multidisciplinary team.
In addition, endoscopists are also responsible for the interpretation of the histopathology of the ESD specimen. The issues here are the following: several histopathological characteristics have different implications for different organs and diseases; the definition of curative and non-curative resection varies between authors; and, in fact, even after a non-curative resection, the probability of a patient being cured is most often higher than the probability of their having residual or distant disease. We therefore recommend that endoscopists should be familiar with the different types of resection, as defined by the ESGE [6]:

Low risk resection (“curative”): low risk for local or distant recurrence; no further immediate therapy is required; is defined as an R0 resection, with no poor prognosis features (less than the cut-off invasion for the specific organ, and no lymphovascular invasion).

Local risk resection: as above, with the exception of positive lateral margins; even though this type of resection increases the risk of local recurrence, most times the patient will be cured in the long-term, so only endoscopic follow-up and putative treatment is recommended.

High risk resection ("non-curative"): in this case there is a real risk of distant disease and adjuvant treatment should be considered on a case-by-case basis; it is defined as an $\mathrm{R} 1$ resection (positive vertical margins), deep sm invasion (beyond the organ-specific $\mu \mathrm{m}$ limit), poorly differentiated tumor, or lymphovascular invasion.

Endoscopists should know that the specific criteria are different for each organ. ESGE recommends that further decisions should be made by multidisciplinary teams.

\section{RECOMMENDATION}

Ideally, endoscopists properly trained in ESD should start performing ESD at their own center only after an ESD expert has confirmed that they have the knowledge and skills to start performing ESD.

Level of agreement $91 \%$.

\section{RECOMMENDATION}

ESD should be performed only in a setting where early and delayed complications can be managed adequately, namely with the possibility of admitting patients to a ward, and access to appropriate emergency surgical teams for the organ being treated with ESD. In addition, centers performing ESD should have access to expert gastrointestinal pathology.

Level of agreement $100 \%$. 
The decision to start ESD in their own center has several implications for the endoscopy team and in the hospital where ESD is going to be performed. Because ESD has the potential for serious and fatal adverse events, it is our opinion that only someone with the proper training, knowledge, and skills should start a new and risky technique on their own. Moreover, the confirmation that an endoscopist fulfils these requirements cannot be made objectively by that individual. For these reasons, it is our opinion that confirmation of the ability of an endoscopist to start ESD should be made by someone else, ideally an expert in ESD. However, we recognize that a definition of a "recognized ESD expert" is lacking. We suggest that a recognized ESD expert could be a person with extensive experience in ESD, with more than 100 ESDs performed and receiving referrals from other hospitals on a regular basis. This recognition of competence should preferably be provided by the ESD expert who has provided training. An ideal scenario would be for an endoscopist to perform their first ESD procedure by themselves in their own center but with the expert present in the endoscopy room.

With regard to the centers in which ESD can be performed, it is ESGE's opinion that ESD cannot be done in every center. Independently of the quality and skills of the endoscopist, the possibility of significant bleeding and perforation is always present and only centers that can handle these complications should be certified to perform ESD. In Japan and Asia, patients undergoing ESD are usually admitted to hospital for several days [67], in contrast to Western countries where they are only admitted for 1 - 2 days [68] or even treated as outpatients [69]. Nevertheless, it appears that a treatment strategy with at least the possibility of admitting the patient to the hospital is fundamental to forearm a serious adverse event [70]. Moreover, even though most ESD complications can be solved endoscopically, surgery may be needed in almost $1 \%$ of procedures, particularly in centers with less experience [71]. For all these reasons, it is our opinion that ESD should be performed only in a center where complications can be managed adequately, namely with the possibility of admitting patients to a ward, and access to appropriate emergency surgical teams for the organ being treated with ESD.

In addition, it is ESGE's opinion that centers performing ESD should have access to expert GI pathology. The histopathological diagnosis of an endoscopic resection specimen is the basis for further clinical decision-making (low vs. high vs. local risk resection; need for further treatment or not) [6]. Therefore, the report on the specimen needs to include all the relevant information required to make that decision. For all ESD specimens, the following risk factors have to be reported: depth of invasion, lymphatic vessel permeation, blood vessel permeation, budding (for colorectal lesions), perineural invasion, resection margin involvement, as well as typing and grading of the neoplasia according to the World Health Organization (WHO) classification [6]. It is our opinion that this can be made in a proper manner only by an expert GI pathologist who has continuous interaction with the endoscopist, ideally in an oncological multidisciplinary team.

\section{RECOMMENDATION}

In order to maintain proficiency in ESD, ESGE recommends a minimum case load of 25 ESD procedures per year.

Level of agreement $100 \%$.

\section{RECOMMENDATION}

All procedures should be registered in a prospective database covering items such as endoscopic classification, location and size of the lesion, technique used, en bloc resection rate, complication rates, time of procedure, R0 resection rate, and final histopathology (including type of resection). En bloc resection rates should be above $90 \%$, and the perforation rate should be below $3 \%$, with a lower than $1 \%$ need for surgery because of complications.

Level of agreement $95 \%$.

The volume of ESDs performed per year appears to be a very important factor as it correlates strongly with most of the outcome measures and rates of complications [72]. This appears more important for colorectal than for upper GI ESD. A metaanalysis comparing Eastern vs. Western ESD results concluded that Eastern results (with a larger case load) were better, but this was particularly true for colorectal ESD and less clear for esophageal and gastric ESD [73]. This appears more dependent on the experience of the endoscopist than on whether they are Eastern or Western [74]. Indeed, in a larger Eastern colorectal ESD series, including 10 institutions, performing less than 50 ESDs (total) was an independent risk factor for an increased number of complications [75]. The authors concluded that performing ESD on a regular basis is important for improving outcomes with less complications. Fuccio et al. calculated that performing at least two ESDs per month is important in achieving higher $\mathrm{R} 0$ and en bloc resection rates, with a lower incidence of adverse events requiring surgery and lower recurrence rates [72].

Although beyond the scope of this specific ESD postgraduate curriculum training, ESGE recommends a minimum case load of 25 ESDs per year in order to maintain proficiency in the technique. Ideally, these 25 ESD procedures per year should be counted separately for the different organs. However, we may argue that proficiency lies in the technique and the technique is similar for every organ. Moreover, it does not seem realistic to perform 25 ESDs per organ per year in every reference center and, for this reason, ESGE advise setting the minimum standard as 25 ESDs per year, independently of the organ. Future studies should compare the outcomes of centers with different case loads (and case loads in different organs) in order to set a more evidence-based recommendation for the minimum volume of ESDs per year.

In order to answer this and other questions, ESGE recommends that each center performing ESD keeps prospective records of each procedure. Quality indicators for ESD have been proposed [76]. We recommend that the following para- 


\section{(अ) \\ ESGE}

Background: advanced endoscopist

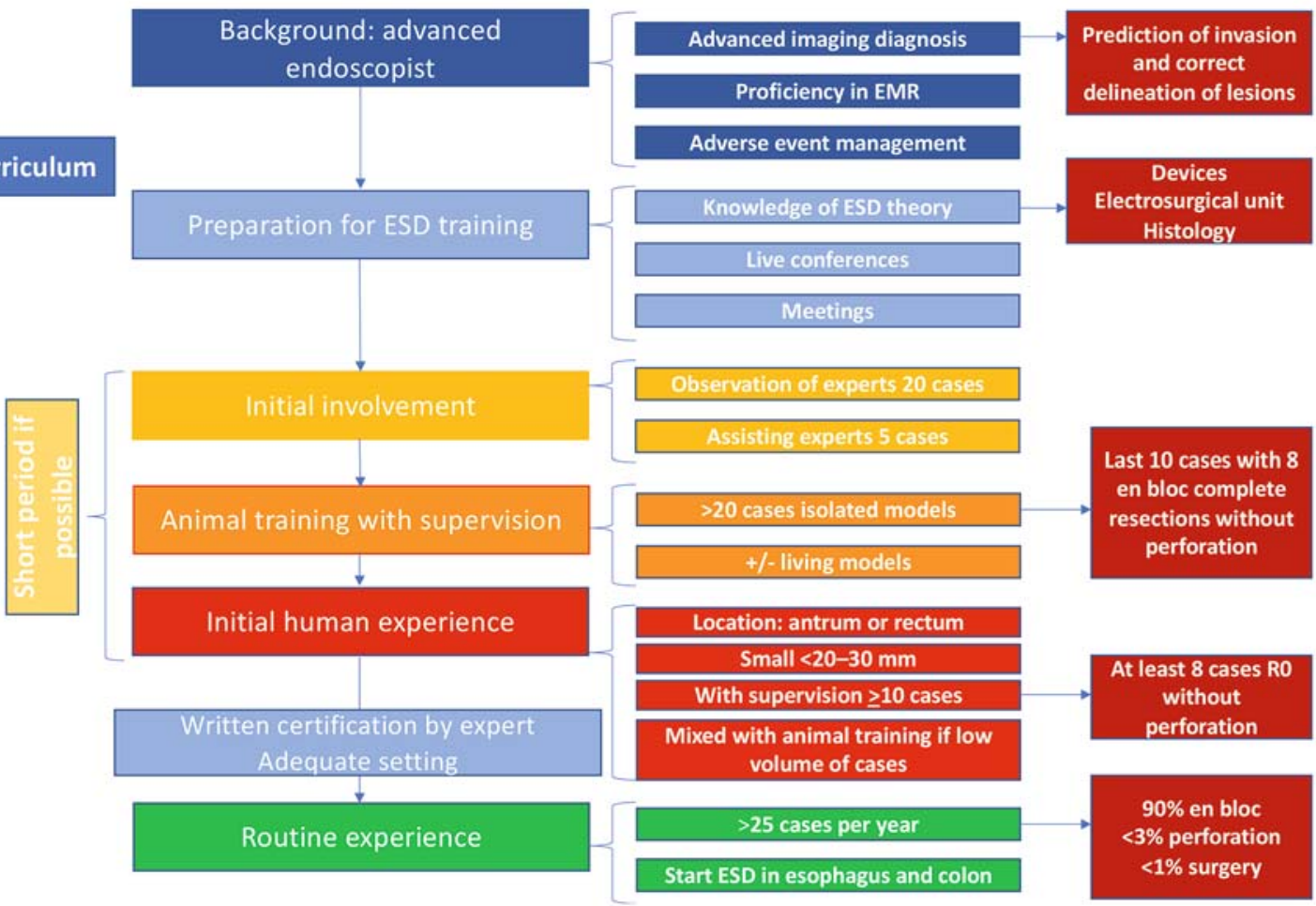

- Fig. 1 Diagram summarizing the ESGE training curriculum for endoscopic submucosal dissection (ESD). EMR, endoscopic mucosal resection. Source: ESGE.

meters should always be recorded for each procedure: lesion characteristics (including advanced imaging diagnosis and Paris classification); general (esophagus, gastric, colorectal) and specific location (upper or lower stomach, rectum or sigmoid); size of the lesion; technique used (ESD, hybrid, tunneling); en bloc (endoscopic) and R0 (histologic) resection rates; complication rates (immediate and delayed bleeding, perforation, need for surgery because of complications, length of hospital stay); time of procedure; and type of resection according to final histopathology result (low, local or high risk resection). Follow-up variables should also be recorded, such as recurrence, metachronous lesions, surgery because of non-curative resection or because of recurrence, and medications that can interfere with outcomes (such as proton pump inhibitors, aspirin, nonsteroidal anti-inflammatory drugs [NSAIDs], and anticoagulants). A clinical database suggested by ESGE for ESD training is available on the ESGE website (https://www.esge. com/esd-training-curriculum/).

Given all the available evidence and published meta-analyses $[72,73,77]$, ESGE recommends that the goal of every endoscopist performing ESD should be to achieve a higher than $90 \%$ en bloc resection rate, with a lower than $3 \%$ perforation rate. Ideally, R0 resections rates of at least $80 \%-85 \%$ should be the goal. However, we do recognize that this goal may be unrealistic, even for expert endoscopists, given that ever bigger and more advanced lesions are being referred for endoscopic resec- tion. Nevertheless, as correct evaluation of the lesion and decision-making with regard to the proper indication for ESD should be a prerequisite for an ESD endoscopist, we do recommend that the goal for the rate of low risk resection ("curative") should be above $75 \%$.

Because bleeding depends on too many factors, sometimes completely independent of the technique (such as medication), we have not set a specific goal for the bleeding rate. Nevertheless, endoscopists performing ESD must be able to solve most of these adverse events without surgery, so we recommend that the need for surgery because of complications should occur in fewer than $1 \%$ of procedures. Regarding the need for surgery because of non-curative resection, this depends more on the characteristics of the lesion than on the ESD technique and no goal has been set.

\section{Conclusions}

This ESGE position statement comprehensively addresses the major steps in the ESD training program. ESD needs specific meticulous skills and dedicated training to achieve competency. The ability to perform a curative resection by ESD without surgery allows us to provide significant benefits to our patients.

The diverse topics covered in this curriculum include the baseline experience needed in diagnostic and therapeutic endoscopy before ESD training; the basic theoretical knowl- 
edge of the devices, strategy, and histological issues; the ways to obtain this knowledge; the initial hands-on training in animal models under supervision; the best choice of sites for the first procedures in humans under supervision; the number of procedures to become trained in the different locations; and the minimum number of procedures to maintain proficiency ( Fig. 1).

As learning curves may be different from one trainee to another, this ESGE curriculum states a quality threshold for ESD in animal models of an en bloc complete resection rate above $80 \%$ and no perforations in the last 10 consecutive procedures before starting human procedures. Once an endoscopist has started performing ESD in humans, ESGE also highlights the need to audit ESD procedures to monitor quality and safety.

Throughout this ESGE curriculum, areas where further research is required to answer critical questions are highlighted, providing direction for researchers to design future studies. We look forward to the opportunity to incorporate the results of such studies into updates of this curriculum in the years to come.

\section{Disclaimer}

ESGE Position Statements represent a consensus of best practice based on the available evidence at the time of preparation. This is NOT a guideline but a proposal for training in ESD. The statements may not apply in all situations and should be interpreted in the light of specific clinical situations and resource availability. Further controlled clinical studies may be needed to clarify aspects of these statements, and revision may be necessary as new data appear. Clinical considerations may justify a course of action at variance with these recommendations.

This ESGE Position Statement is intended to be an educational device to provide information that may assist endoscopists in providing care to patients. The recommendations are not rules and should not be construed as establishing a legal standard of care or as encouraging, advocating, requiring, or discouraging any particular treatment.

The legal disclaimer for ESGE guidelines applies to the present position statement [4].

\section{Acknowledgments}

The authors gratefully thank Arjun Koch, Diogo Libânio, Francisco Baldaque da Silva, George Cortas, Gianluca Esposito, Jacques Bergman, Krish Ragunath, Miguel Areia, Oliver Pech, and Ricardo Kuttner Magalhães for participating in the voting process and for their critical review of this Curriculum.

R. Bisschops is funded by the Research Foundation - Flanders. J. E. East was funded by the National Institute for Health Research (NIHR) Oxford Biomedical Research Centre. The views expressed are those of the author(s) and not necessarily those of the National Health Service, the NIHR, or the Department of Health.
Competing interests

F. Berr has received financial support from Ethical MedTech (Olympus, Fujifilm, ERBE, and others) to organize medical education courses and live endoscopy events (2009-2019), and speaker's fees from Olympus (2015-2018). R. Bisschops has received research support from Cook and Medtronic, and financial support for symposium organization from Cook, Boston Scientific, Olympus, and Erbe (2009-2019), and speaker's fees from Boston Scientific and Medtronic (20092019). E. Dekker has received speaker's fees from Olympus, Roche, and GI Supply, has provided consultancy to Fujifilm, Olympus, Tillots, GI Supply, and CPP-FAP, and is a member of the supervisory board of eNose; she receives a research grant from Fujifilm (2017 to present). P. Deprez has provided consultancy to Olympus, Erbe, and Boston Scientific (2015-2019). M. Dinis-Ribeiro is co-editor in-chief of Endoscopy. J. E. East received speaker's fees from Olympus and Falk (2018) and is on the clinical advisory boards of Boston Scientific and Lumendi (2016 to present). G. Johnson has served on advisory boards for Boston Scientific and Olympus (2017) and Medtronic (2018), and has been a faculty member for annual training courses supported by Olympus (2014 to present) and Boston Scientific (2017 to present). B. L. A. M. Weusten received financial support for clinical and preclinical research from Pentax Medical Nature (2018 to 2019). E. Albéniz, M. Arvanitakis, P. Dewint, A. Ebigbo, A Haji, A. Panarese, P. PimentelNunes, M. Pioche, T. Ponchon, and D. S. Sanders have no competing interests.

References

[1] Ribeiro-Mourao F, Pimentel-Nunes P, Dinis-Ribeiro M. Endoscopic submucosal dissection for gastric lesions: results of an European inquiry. Endoscopy 2010; 42: 814-819

[2] Cao Y, Liao C, Tan A et al. Meta-analysis of endoscopic submucosal dissection versus endoscopic mucosal resection for tumors of the gastrointestinal tract. Endoscopy 2009; 41: 751 - 757

[3] Parra-Blanco A, Gonzalez N, Arnau MR. Ex vivo and in vivo models for endoscopic submucosal dissection training. Clin Endosc 2012; 45: $350-357$

[4] Dumonceau JM, Hassan C, Riphaus A et al. European Society of Gastrointestinal Endoscopy (ESGE) Guideline Development Policy. Endoscopy 2012; 44: 626-629

[5] Bisschops R, Dekker E, East JE et al. European Society of Gastrointestinal Endoscopy (ESGE) curricula development for postgraduate training in advanced endoscopic procedures: rationale and methodology. Endoscopy 2019: doi:10.1055/a-1000-5603

[6] Pimentel-Nunes P, Dinis-Ribeiro M, Ponchon T et al. Endoscopic submucosal dissection: European Society of Gastrointestinal Endoscopy (ESGE) Guideline. Endoscopy 2015; 47: 829-854

[7] Dinis-Ribeiro M, Areia M, de Vries AC et al. Management of precancerous conditions and lesions in the stomach (MAPS): guideline from the European Society of Gastrointestinal Endoscopy (ESGE), European Helicobacter Study Group (EHSG), European Society of Pathology (ESP), and the Sociedade Portuguesa de Endoscopia Digestiva (SPED). Endoscopy 2012; 44: 74 - 94

[8] Ferlitsch M, Moss A, Hassan C et al. Colorectal polypectomy and endoscopic mucosal resection (EMR): European Society of Gastrointestinal Endoscopy (ESGE) Clinical Guideline. Endoscopy 2017; 49: $270-297$

[9] Endoscopic Classification Review Group. Update on the Paris classification of superficial neoplastic lesions in the digestive tract. Endoscopy 2005; $37: 570-578$ 
[10] Inoue $\mathrm{H}$, Kaga $\mathrm{M}$, Ikeda $\mathrm{H}$ et al. Magnification endoscopy in esophageal squamous cell carcinoma: a review of the intrapapillary capillary loop classification. Ann Gastroenterol 2015; 28: 41 - 48

[11] Oyama T, Inoue H, Arima M et al. Prediction of the invasion depth of superficial squamous cell carcinoma based on microvessel morphology: magnifying endoscopic classification of the Japan Esophageal Society. Esophagus 2017; 14: 105-112

[12] Uraoka T, Saito Y, Ikematsu H et al. Sano's capillary pattern classification for narrow-band imaging of early colorectal lesions. Dig Endosc 2011; 23: (Suppl. 01): $112-115$

[13] Pimentel-Nunes P, Dinis-Ribeiro M, Soares JB et al. A multicenter validation of an endoscopic classification with narrow band imaging for gastric precancerous and cancerous lesions. Endoscopy 2012; 44: $236-246$

[14] Pimentel-Nunes P, Libanio D, Lage J et al. A multicenter prospective study of the real-time use of narrow-band imaging in the diagnosis of premalignant gastric conditions and lesions. Endoscopy 2016; 48: $723-730$

[15] Yao K, Anagnostopoulos GK, Ragunath K. Magnifying endoscopy for diagnosing and delineating early gastric cancer. Endoscopy 2009; 41: $462-467$

[16] Yao K, Oishi T, Matsui T et al. Novel magnified endoscopic findings of microvascular architecture in intramucosal gastric cancer. Gastrointest Endosc 2002; 56: 279-284

[17] Abe S, Oda I, Shimazu T et al. Depth-predicting score for differentiated early gastric cancer. Gastric Cancer 2011; 14: 35-40

[18] Kudo S, Rubio CA, Teixeira CR et al. Pit pattern in colorectal neoplasia: endoscopic magnifying view. Endoscopy 2001; 33: 367-373

[19] Hayashi N, Tanaka S, Hewett DG et al. Endoscopic prediction of deep submucosal invasive carcinoma: validation of the narrow-band imaging international colorectal endoscopic (NICE) classification. Gastrointest Endosc 2013; 78: 625-632

[20] Iwatate M, Sano Y, Tanaka S et al. Validation study for development of the Japan NBI Expert Team classification of colorectal lesions. Dig Endosc 2018; 30: $642-651$

[21] Sumimoto K, Tanaka S, Shigita K et al. Clinical impact and characteristics of the narrow-band imaging magnifying endoscopic classification of colorectal tumors proposed by the Japan NBI Expert Team. Gastrointest Endosc 2017; 85: 816-821

[22] Goda K, Fujishiro M, Hirasawa K et al. How to teach and learn endoscopic submucosal dissection for upper gastrointestinal neoplasm in Japan. Dig Endosc 2012; 24: (Suppl. 01): $136-142$

[23] Kakushima N, Hirasawa K, Morita Y et al. Terminology for training of endoscopic submucosal dissection. Dig Endosc 2012; 24: (Suppl. 01): $133-135$

[24] Tsuji Y, Ohata K, Sekiguchi M et al. An effective training system for endoscopic submucosal dissection of gastric neoplasm. Endoscopy 2011; 43: $1033-1038$

[25] Gupta S, Bassett P, Man R et al. Validation of a novel method for assessing competency in polypectomy. Gastrointest Endosc 2012; 75: $568-575$

[26] Chong DH, Poon CM, Leong HT. Colorectal endoscopic submucosal dissection at a low-volume centre: tips and tricks, and learning curve in a district hospital in Hong Kong. Hong Kong Med J 2016; 22: 256 262

[27] Yamamoto S, Uedo N, Ishihara R et al. Endoscopic submucosal dissection for early gastric cancer performed by supervised residents: assessment of feasibility and learning curve. Endoscopy 2009; 41: $923-928$

[28] Shiga $H$, Endo K, Kuroha M et al. Endoscopic submucosal dissection for colorectal neoplasia during the clinical learning curve. Surg Endosc 2014; 28: $2120-2128$
[29] lacopini F, Bella A, Costamagna G et al. Stepwise training in rectal and colonic endoscopic submucosal dissection with differentiated learning curves. Gastrointest Endosc 2012; 76: $1188-1196$

[30] Pioche M, Rivory J, Aguero-Garcete $G$ et al. New isolated bovine colon model dedicated to colonic ESD hands-on training: development and first evaluation. Surg Endosc 2015; 29: 3209-3215

[31] Pioche M, Rivory J, Nishizawa T et al. Randomized comparative evaluation of endoscopic submucosal dissection self-learning software in France and Japan. Endoscopy 2016; 48: 1076-1083

[32] Kim EY, Jeon SW, Kim GH. Chicken soup for teaching and learning ESD. World J Gastroenterol 2011; 17: 2618-2622

[33] Rahmi G, Hotayt B, Chaussade S et al. Endoscopic submucosal dissection for superficial rectal tumors: prospective evaluation in France. Endoscopy 2014; 46: 670-676

[34] Berr F, Ponchon T, Neureiter D et al. Experimental endoscopic submucosal dissection training in a porcine model: learning experience of skilled Western endoscopists. Dig Endosc 2011; 23: 281-289

[35] Kuttner-Magalhaes R, Dinis-Ribeiro M, Bruno M] et al. Training in endoscopic mucosal resection and endoscopic submucosal dissection: Face, content and expert validity of the live porcine model. United European Gastroenterol J 2018; 6: 547- 557

[36] Hong KH, Shin SJ, Kim JH. Learning curve for endoscopic submucosal dissection of gastric neoplasms. Eur J Gastroenterol Hepatol 2014; 26: 949-954

[37] Jeon HH, Lee HS, Youn YH et al. Learning curve analysis of colorectal endoscopic submucosal dissection (ESD) for laterally spreading tumors by endoscopists experienced in gastric ESD. Surg Endosc 2016; 30: $2422-2430$

[38] Kato M, Gromski M, Jung Y et al. The learning curve for endoscopic submucosal dissection in an established experimental setting. Surg Endosc 2013; 27: $154-161$

[39] Sakamoto T, Saito Y, Fukunaga $S$ et al. Learning curve associated with colorectal endoscopic submucosal dissection for endoscopists experienced in gastric endoscopic submucosal dissection. Dis Colon Rectum 2011; 54: $1307-1312$

[40] Oda I, Odagaki T, Suzuki H et al. Learning curve for endoscopic submucosal dissection of early gastric cancer based on trainee experience. Dig Endosc 2012; 24: (Suppl. 01): 129-132

[41] Gromski MA, Cohen J, Saito K et al. Learning colorectal endoscopic submucosal dissection: a prospective learning curve study using a novel ex vivo simulator. Surg Endosc 2017; 31: 4231 - 4237

[42] Martinek J, Suchanek S, Stefanova M et al. Training on an ex vivo animal model improves endoscopic skills: a randomized, single-blind study. Gastrointest Endosc 2011; 74: 367-373

[43] Iacopini F, Saito Y, Bella A et al. Colorectal endoscopic submucosal dissection: predictors and neoplasm-related gradients of difficulty. Endosc Int Open 2017; 5: E839-E846

[44] Bhatt A, Abe S, Kumaravel A et al. Video-based supervision for training of endoscopic submucosal dissection. Endoscopy 2016; 48: 711 716

[45] Draganov PV, Chang M, Coman RM et al. Role of observation of live cases done by Japanese experts in the acquisition of ESD skills by a western endoscopist. World J Gastroenterol 2014; 20: 4675-4680

[46] Hirasawa K, Kokawa A, Oka H et al. Risk assessment chart for curability of early gastric cancer with endoscopic submucosal dissection. Gastrointest Endosc 2011; 74: 1268 - 1275

[47] Ono S, Kato M, Nakagawa M et al. Outcomes and predictive factors of "not self-completion" in gastric endoscopic submucosal dissection for novice operators. Surg Endosc 2013; 27: 3577 -3583

[48] Shiga H, Kuroha M, Endo K et al. Colorectal endoscopic submucosal dissection (ESD) performed by experienced endoscopists with limited experience in gastric ESD. Int J Colorectal Dis 2015; 30: 1645-1652 
[49] Sakamoto T, Sato C, Makazu M et al. Short-term outcomes of colorectal endoscopic submucosal dissection performed by trainees. Digestion 2014; 89: 37-42

[50] Yang DH, Jeong GH, Song Y et al. The feasibility of performing colorectal endoscopic submucosal dissection without previous experience in performing gastric endoscopic submucosal dissection. Dig Dis Sci 2015; 60: $3431-3441$

[51] Spychalski M, Dziki A. Safe and efficient colorectal endoscopic submucosal dissection in European settings: is successful implementation of the procedure possible? Dig Endosc 2015; 27: 368-373

[52] Niimi K, Fujishiro M, Goto O et al. Safety and efficacy of colorectal endoscopic submucosal dissection by the trainee endoscopists. Dig Endosc 2012; 24: (Suppl. 01): 154-158

[53] Ebigbo A, Probst A, Rommele C et al. Step-up training for colorectal and gastric ESD and the challenge of ESD training in the proximal coIon: results from a German Center. Endosc Int Open 2018; 6: E524E530

[54] Ronnow CF, Uedo N, Toth E et al. Endoscopic submucosal dissection of 301 large colorectal neoplasias: outcome and learning curve from a specialized center in Europe. Endosc Int Open 2018; 6: E1340 -E1348

[55] Deprez PH, Bergman JJ, Meisner S et al. Current practice with endoscopic submucosal dissection in Europe: position statement from a panel of experts. Endoscopy 2010; 42: 853-858

[56] Gotoda T, Friedland S, Hamanaka $\mathrm{H}$ et al. A learning curve for advanced endoscopic resection. Gastrointest Endosc 2005; 62: 866 867

[57] Hotta K, Oyama T, Shinohara T et al. Learning curve for endoscopic submucosal dissection of large colorectal tumors. Dig Endosc 2010; 22: $302-306$

[58] Jacques ], Legros R, Charissoux A et al. A local structured training program with live pigs allows performing ESD along the gastrointestinal tract with results close to those of Japanese experts. Dig Liver Dis 2016; 48: $1457-1462$

[59] Choi HS, Chun H]. Accessory devices frequently used for endoscopic submucosal dissection. Clin Endosc 2017; 50: 224-233

[60] Mavrogenis G, Hochberger ], Deprez P et al. Technological review on endoscopic submucosal dissection: available equipment, recent developments and emerging techniques. Scand J Gastroenterol 2017; 52: $486-498$

[61] Jacques ], Legros R, Rivory J et al. The "tunnel + clip" strategy standardised and facilitates oesophageal ESD procedures: a prospective, consecutive bi-centric study. Surg Endosc 2017; 31: 4838-4847

[62] Lupu A, Jacques J, Rivory J et al. Endoscopic submucosal dissection with triangulated traction with clip and rubber band: the "wallet" strategy. Endoscopy 2018; 50: E256-E258
[63] Esaki M, Suzuki S, Hayashi Y et al. Splash M-knife versus Flush Knife BT in the technical outcomes of endoscopic submucosal dissection for early gastric cancer: a propensity score matching analysis. BMC Gastroenterol 2018; 18: 35

[64] Zhou PH, Schumacher B, Yao LQ et al. Conventional vs. waterjetassisted endoscopic submucosal dissection in early gastric cancer: a randomized controlled trial. Endoscopy 2014; 46: 836-843

[65] Morita Y. Electrocautery for ESD: settings of the electrical surgical unit VIO300D. Gastrointest Endosc Clin N Am 2014; 24: 183-189

[66] Libanio D, Dinis-Ribeiro M, Pimentel-Nunes $P$ et al. Predicting outcomes of gastric endoscopic submucosal dissection using a Bayesian approach: a step for individualized risk assessment. Endosc Int Open 2017; 5: E563-E572

[67] Kim MY, Cho JH, Jain P et al. ESD around the world: Asia. Gastrointest Endosc Clin N Am 2014; 24: 283 - 293

[68] Pimentel-Nunes P, Mourao F, Veloso $\mathrm{N}$ et al. Long-term follow-up after endoscopic resection of gastric superficial neoplastic lesions in Portugal. Endoscopy 2014; 46: $933-940$

[69] Santos-Antunes J, Baldaque-Silva F, Marques M et al. Real-life evaluation of the safety, efficacy and therapeutic outcomes of endoscopic submucosal dissection in a Western tertiary centre. United European Gastroenterol J 2018; 6: 702 - 709

[70] Oda I, Suzuki H, Nonaka S et al. Complications of gastric endoscopic submucosal dissection. Dig Endosc 2013; 25: (Suppl. 01): 71 - 78

[71] Chung IK, Lee JH, Lee SH et al. Therapeutic outcomes in 1000 cases of endoscopic submucosal dissection for early gastric neoplasms: Korean ESD Study Group multicenter study. Gastrointest Endosc 2009; 69: $1228-1235$

[72] Fuccio L, Hassan C, Ponchon T et al. Clinical outcomes after endoscopic submucosal dissection for colorectal neoplasia: a systematic review and meta-analysis. Gastrointest Endosc 2017; 86: 74 - 86 e17

[73] Daoud DC, Suter N, Durand M et al. Comparing outcomes for endoscopic submucosal dissection between Eastern and Western countries: A systematic review and meta-analysis. World J Gastroenterol 2018; 24: $2518-2536$

[74] Catalano F, Mengardo V, Trecca A et al. The impact of experience on short- and long-term outcomes on gastric ESD: a western series. Updates Surg 2019: doi:10.1007/s13304-019-00628-1

[75] Saito Y, Uraoka T, Yamaguchi Y et al. A prospective, multicenter study of 1111 colorectal endoscopic submucosal dissections (with video). Gastrointest Endosc 2010; 72: 1217-1225

[76] Fuccio L, Bhandari P, Maselli R et al. Ten quality indicators for endoscopic submucosal dissection: what should be monitored and reported to improve quality. Ann Transl Med 2018; 6: 262

[77] Lian J, Chen S, Zhang Y et al. A meta-analysis of endoscopic submucosal dissection and EMR for early gastric cancer. Gastrointest Endosc 2012; 76: $763-770$ 